\title{
Algorithm of adaptation results tractors tractive tests based on systems OECD and ISO
}

\author{
Alexander Lavrov ${ }^{1, *}$, Vladimir Shevtsov ${ }^{1}$, and Maksim Sidorov ${ }^{2}$ \\ ${ }^{1}$ Federal Scientific Agroengineering Center VIM, 1-st Institutsky proezd, 5, Moscow, 109428, Russia. \\ ${ }^{2}$ Kaluga branch Russian state agricultural university, st. 7, Kaluga, 248007, Russia.
}

\begin{abstract}
In this paper authors described the algorithm for matching and harmonization the results of traction tests of domestic and foreign tractors according to the OECD and ISO systems. The results of the calculations are entered into the designed database, which contained 5 information blocks and control block. The control unit allows to implement a number of information requests (in terms of operating mass, maximum traction power, etc.). Information of agricultural tractors tests is contained in this database, test were made in Germany (11 models), France ( 8 models), Italy ( 8 models), and Austria, India, South Korea (over 37 models) according to OECD standards, each model tested on 2 type of covering: concrete and stubble.
\end{abstract}

\section{Introduction}

Now days there are more 100 models of imported tractors [1] on the Russian market. It is necessary to consider their characteristics. On the one hand it would be obtained in comparable conditions, and at the same time, it made possible to evaluate the effectiveness of using different models in specific national conditions. At first, we should include traction indicators of agricultural tractors to these characteristics. It is necessary to analyze two tractor test systems. First one is the European system (based on ISO standards), and the second one is CODE 2 («OECD STANDARD CODES FOR THE OFFICIAL TESTING OF AGRICULTURAL AND FORESTRY TRACTOR»). This system has found international recognition $[2,3]$.

This problem was solving in Research Institute «RosNIITM» in several years, but current practice solving are based without correlation with traction classes $[4,5,6]$. However, it is necessary to more strictly assess the discrepancies between the GOST (ISO) and the OECD. The database of agricultural tractors traction indicators was developed to harmonization ISO standard and OECD standard, as well as for predicting the operation indicators of the foreign machine tractors unit (MTU) in the Russian economic conditions. We provided the calculations characteristics of MTU operated on the stubble in our database. It made for rational aggregation of foreign tractors with an evaluation of traction properties on the concrete. We have test protocol of traction indicators on the stubble for

\footnotetext{
* Corresponding author: vimlavrov@mail.ru
} 
Russians tractors, it was calculated characteristics on concrete, which allows comparison with foreign models on the Russian market [7, 8].

Aim of this research is design of the algorithm of adaptation the maximum power on the drawbar device to the indicators of the traction-power classification of the tractors type in Russia Also result of research will be design of database of Russian and foreign agricultural tractors defined by Interstate (ISO) and OECD standards.

\section{Materials and methods}

We considered the results of traction tests which recorded in the test reports of the OECD standard and ISO standard as source information. It was used order of research of the traction indicators determination according to the OECD standard [2, 9, 10]. The Russian peculiarity is the simultaneous application of the ISO-789 standards, State Standards (GOST), Interstate standards which adopted in the different countries (the Republic of Azerbaijan; Republic of Armenia; Republic of Belarus; Georgia; The Republic of Kazakhstan; Republic of Kyrgyzstan; The Republic of Moldova; Russian Federation; The Republic of Tajikistan; Turkmenistan; The Republic of Uzbekistan; Ukraine). We presented such standards:

- GOST 7057-2001 «Agricultural tractors. Test methods». Instead, GOST 7057-81. Date of introduction - 01.01.2003;

- GOST 30745-2001 (ISO 789-9-90) «Agricultural tractors. Definition of traction indicators». Introduction date - 01.01.2003;

- GOST 30747-2001 (ISO 789-1-90) «Agricultural tractors. Definition of test indicators through a power take-off shaft» Introduction date - 01.01.2003;

The general methodology of harmonization included the following stages:

- analysis of available protocol materials based on the results of traction tests according to OECD and ISO systems;

- design algorithm to bring the results of determining the maximum power on the coupling device according to the OECD standard to the indicators of the traction-power classification of the tractors type in Russia;

- design database of traction indicators of Russian and foreign agricultural tractors which defined by the ISO and OECD standards.

\section{Results and discussions}

It was applied the index «c» to the concrete test (measured according to the OECD standard) and the index «s» to the stubble test in process of designing the algorithm of the traction indicators of a wheeled tractor. Let's consider the algorithm based on the analysis of forces and power flows in Figure 1. 


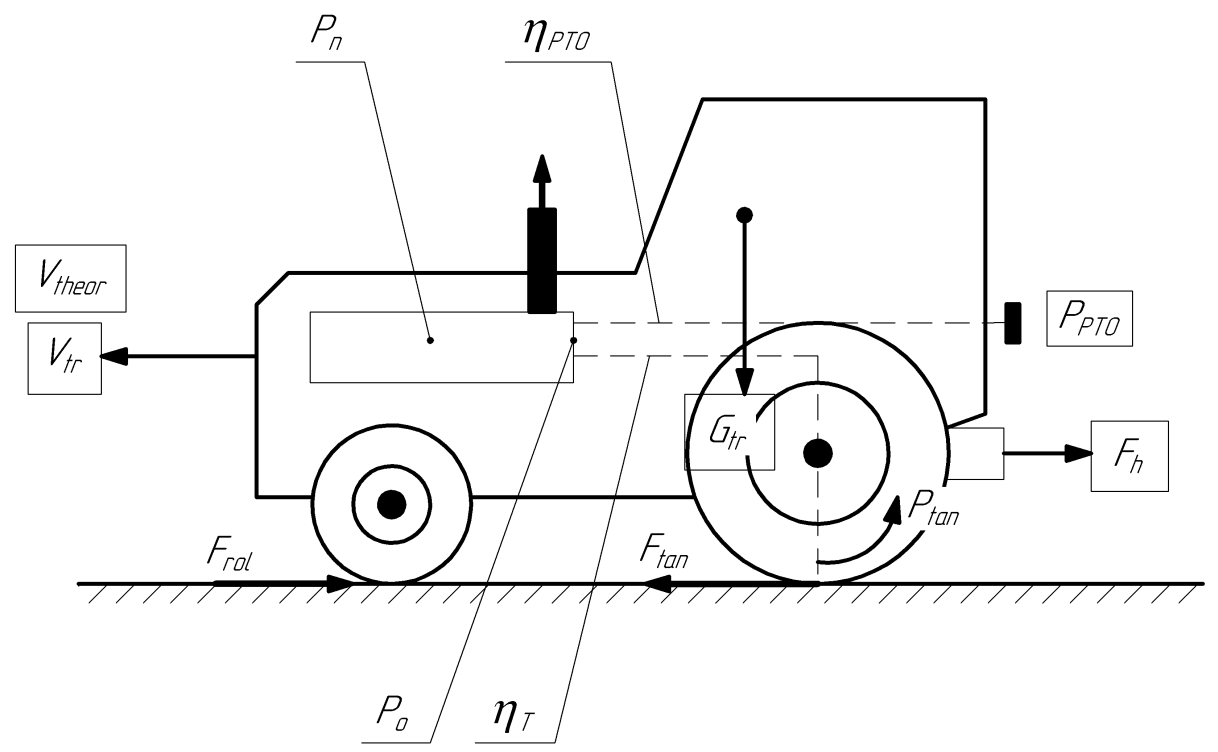

Fig. 1. Scheme of forces and power flows acting on the tractor with traction tests.

Measuring indicators are given in the test protocol at maximum pulling power (according to the OECD system) (Figure 2).

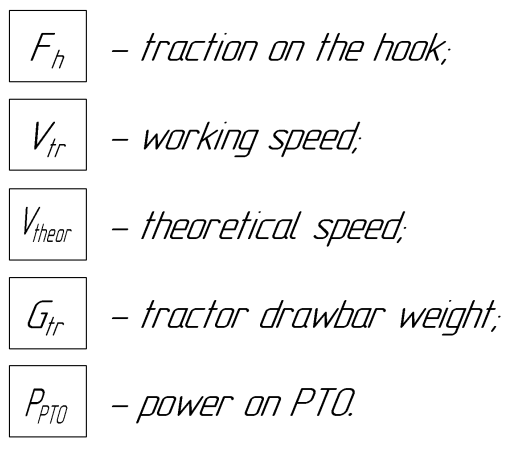

Fig. 2. Measuring indicators according to the OECD standard.

Values of the measuring indicators were given at the maximum traction power from the test report.

$$
\left(P_{o}=0,9 \cdot P_{n}-\text { operational engine power. } P_{o}=\frac{P_{P T O}}{\eta_{P T O}}\right) .
$$

Required to determine the conditions on the stubble:

$$
F_{h}^{s}, V_{t r}^{s}, P_{h}^{s}, \eta_{t r}^{s} \text { при } \delta^{s}=15 \%\left(\eta_{\delta}^{s}=\frac{100-\delta^{s}}{100}=0,85\right),
$$

and equal theoretical speeds: 


$$
V_{\text {theor }}=\frac{V_{t r}^{c}}{\eta_{\delta}^{c}}=\frac{V_{t r}^{s}}{\eta_{\delta}^{s}} \text { or } \frac{V_{t r}^{c}}{1-\delta^{c}}=\frac{V_{t r}^{s}}{1-\delta^{s}}, \text { where }
$$

1) Determination actual speed on the stubble.

$$
V_{t r}^{s}=\frac{V_{t r}^{c}}{\eta_{\delta}^{c}} \cdot \eta_{\delta}^{s}=\frac{V_{t r}^{c}}{\left(1-\delta^{c}\right)} \cdot\left(1-\delta^{s}\right)=0,85 \cdot \frac{V_{t r}^{s}}{1-\eta_{\delta}^{c}} .
$$

2) Definition of tractive force on the stubble.

From the equation of traction power on the stubble:

$$
F_{h}^{s} \cdot V_{t r}^{s}=N_{\tan } \cdot \eta_{\delta}^{s}-F_{r o l}^{s} \cdot V_{t r}^{s},
$$

get traction equation:

$$
F_{h}^{s}=\frac{P_{\tan }^{s} \cdot \eta_{\delta}^{s}-F_{r o l}^{s} \cdot V_{t r}^{s}}{V_{t r}^{s}} .
$$

From the equation of traction power on the concrete

$$
P_{\tan }^{c}=\frac{F_{h}^{c} \cdot V_{t r}^{c}+F_{r o l}^{c} \cdot V_{t r}^{c}}{\eta_{\delta}^{c}} .
$$

Substituting (3) and (1) in (2), we will get:

$$
F_{h}^{s}=\frac{\frac{\left(F_{h}^{c} \cdot V_{t r}^{c}+F_{r o l}^{c} \cdot V_{t r}^{c}\right)}{\eta_{\delta}^{c}} \cdot \eta_{\delta}^{s}-F_{r o l}^{s} \cdot \frac{V_{t r}^{c}}{\eta_{\delta}^{c}} \cdot \eta_{\delta}^{s}}{\frac{V_{t r}^{c}}{\eta_{\delta}^{c}} \cdot \eta_{\delta}^{s}}
$$

or

$F_{h}^{s}=F_{h}^{c}+F_{r o l}^{c}-F_{t r}^{s}$; or according with $F_{r o l}^{c}=G_{t r} \cdot f_{c} ; F_{r o l}^{s}=G_{t r} \cdot f_{s}$, we will get:

$$
F_{h}^{s}=F_{h}^{c}-G_{t r} \cdot\left(f_{s}-f_{c}\right),
$$

where: $f_{c} ; f_{s}$ - the rolling resistance coefficients of the tractor on the concrete and the stubble, accordingly (Table 1).

Table 1. Rolling resistance coefficients

\begin{tabular}{|c|c|c|}
\hline Type of covering & Wheel tractor & Caterpillar tractor \\
\hline Concrete, $f_{c}$ & 0,018 & $0,035 \ldots 0,045$ \\
\hline Stublle, $f_{s}$ & $0,10 \ldots 0,12$ & $0,07 \ldots 0,08$ \\
\hline
\end{tabular}

For wheel tractor: $f_{s}=0,11 ; f_{c}=0,018 ; F_{h}^{s}=F_{h}^{c}-0,092 G_{t r}$.

For caterpillar tractor: $f_{s}=0,075 ; f_{c}=0,04 ; F_{h}^{s}=F_{h}^{c}-0,035 G_{t r}$.

3) Determination of traction power on the stubble. 


$$
P_{h}^{s}=F_{h}^{s} \cdot V_{t r}^{s}=\left[F_{h}^{c}-G_{t r}\left(f_{s}-f_{c}\right)\right] \cdot \frac{V_{t r}^{c}}{\eta_{\delta}^{c}} \cdot \eta_{\delta}^{s} .
$$

For $\delta^{s}=15 \%$ and $\eta_{\delta}^{s}=0,85$ we will have:

$$
P_{h}^{s}=0,85 \cdot\left[F_{h}^{c}-G_{t r}\left(f_{s}-f_{c}\right)\right] \cdot \frac{V_{t r}^{c}}{\eta_{\delta}^{c}} .
$$

4) Determination of conditional traction efficiency on the stubble.

$$
\eta_{t r}^{s}=\frac{P_{h}^{s}}{P_{o}}=\frac{P_{h}^{s}}{P_{n} \cdot 0,9} .
$$

It was designed the database «Traction indicators of Russian and foreign tractors by Interstate (ISO) and OECD standards at maximum engine power» as a result of processing of the test protocols on the concrete and the stubble, and its calculations [11]. It contained 5 information blocks and control block. These blocks allowed to applicate a number of information requests (by operating weight, maximum traction power, etc.).

It was designed the following database structure in connection with the tasks (Figure 3).

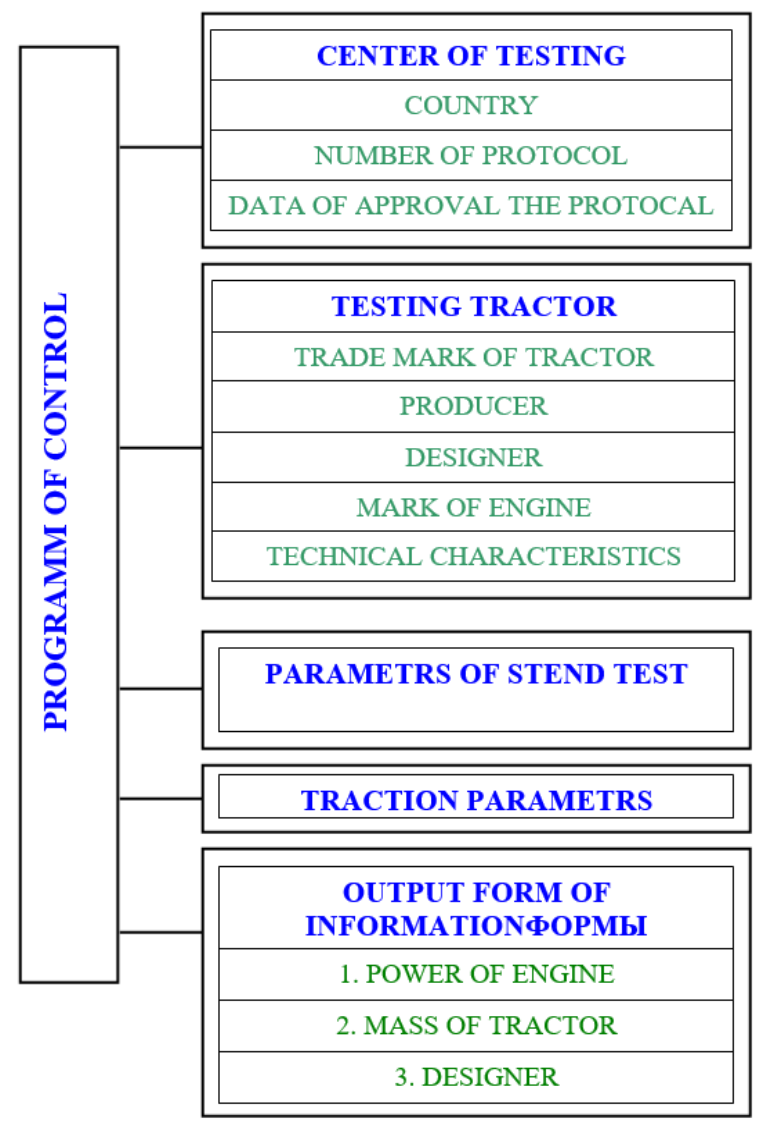

Fig. 3. Block structure of the database of traction indicators of Russian and foreign agricultural tractors 
Information about results of official agricultural tractors tests contains in the database according the rules of OECD standard. These tests were conducted by France CEMAGREF testing center (8 models), Germany DLG testing center (11 models), Italy IMAMOTER testing center ( 8 models), and also testing centers of Austria, India, Republic of Korea (only 37 models), each on 2 covering: concrete and stubble. It was conducted the classification of tractors for traction force.

The control block of the program will allow to calculate the required traction indicators, as well as to make a request to the database in the form of a comparative table of traction indicators on the stubble and the concrete.

An example of the calculation of traction indicators of the Massey Fergusson 7465 agricultural tractor on the stubble is shown in Table 2 .

Table 2. The results of traction tests according to the OECD standard and the results of theoretical calculations of the traction parameters for coordination with the ISO standard

\begin{tabular}{|c|c|c|c|c|c|c|}
\hline \multirow{5}{*}{$\begin{array}{l}\text { Number } \\
\text { of } \\
\text { indicator }\end{array}$} & \multirow{5}{*}{\multicolumn{2}{|c|}{ Indicators }} & \multicolumn{4}{|c|}{ Trade tractor mark } \\
\hline & & & \multirow[b]{2}{*}{$\begin{array}{l}\text { Stubble } \\
\text { (ISO) }\end{array}$} & \multirow[b]{2}{*}{$\begin{array}{l}\text { Concrete } \\
\text { Code2 } \\
\text { (OECD) }\end{array}$} & \multicolumn{2}{|c|}{ Massey Fergusson 7465} \\
\hline & & & & & $\begin{array}{l}\text { Stubble } \\
\text { (ISO) }\end{array}$ & $\begin{array}{l}\text { Concrete } \\
\text { Code2 } \\
\text { (OECD) }\end{array}$ \\
\hline & & & \multicolumn{4}{|c|}{ Number of protocol } \\
\hline & & & 1 & 2 & 3 & 4 \\
\hline 1 & \multicolumn{2}{|r|}{2} & 3 & 4 & 5 & 6 \\
\hline 1 & \multicolumn{2}{|c|}{ Country } & & Protocol & & France \\
\hline 2 & \multicolumn{2}{|c|}{ Test centr } & & Protocol & & $\begin{array}{l}\text { CEMAGREF, } \\
\text { Antony }\end{array}$ \\
\hline 3 & \multicolumn{2}{|c|}{ Number of protocol } & $\begin{array}{c}\text { Evaluati } \\
\text { ng }\end{array}$ & Protocol & DESIGN & 16551 \\
\hline 4 & \multicolumn{2}{|c|}{ Data of approval protocol } & & Protocol & & 16.11 .2010 \\
\hline 5 & \multirow{2}{*}{\multicolumn{2}{|c|}{$\begin{array}{l}\text { Production firm } \\
\text { Designed firm }\end{array}$}} & & 1.1 & & AGCO S.A. \\
\hline 6 & & & & 1.1 & & \\
\hline 7 & \multicolumn{2}{|c|}{ Type of tractor } & & 1.1 & & 4WD \\
\hline 8 & \multicolumn{2}{|c|}{ Type of engine } & & & & $\begin{array}{l}\text { SISU/AGCO } \\
\text { POWER Inc. } \\
\text { 66.633CTA- } \\
\text { 4V/Diesel }\end{array}$ \\
\hline 9 & \multicolumn{2}{|c|}{$\begin{array}{l}\text { Power at PTO at nominal } \\
\text { engine speed, } \mathrm{kW}\end{array}$} & & 3.1 .2 & & 80,4 \\
\hline 10 & \multirow{2}{*}{\multicolumn{2}{|c|}{$\begin{array}{c}\text { Rated engine speed } \\
\text { The volume of } \\
\text { developments, } \mathrm{m} \mathrm{h}\end{array}$}} & & 3.1 .2 & & 2200 \\
\hline 11 & & & & & & \\
\hline 12 & \multicolumn{2}{|c|}{$\begin{array}{c}\text { Maximum power at PTO, } \\
\mathrm{kW}, P_{P T O}^{\max }\end{array}$} & & 3.1 .1 & & 94,0 \\
\hline 13 & \multirow[t]{2}{*}{$\begin{array}{l}\text { Rotation } \\
\text { al speed, } \\
\text { min-1 }\end{array}$} & $\begin{array}{c}\text { Engine } \\
\text { crankshaft, } \\
n_{e P T O}\end{array}$ & & 3.1 .1 & & 2000 \\
\hline 14 & & $\mathrm{PTO}, n_{\text {PTO }}$ & & 3.1 .1 & & 983 \\
\hline 15 & \multicolumn{2}{|c|}{$\begin{array}{c}\text { Transmission efficiency } \\
\text { from engine to PTO } \\
\text { accepted }\end{array}$} & & & 0,93 & 0,93 \\
\hline 16 & \multicolumn{2}{|c|}{$\begin{array}{c}\text { Maximum engine } \\
\text { operating power, } \mathrm{kW} \\
P_{o}^{\max }\end{array}$} & & & 101,1 & 101,1 \\
\hline 17 & \multicolumn{2}{|c|}{ Transmission type } & & 1.3 & & $\begin{array}{c}\text { Hidrostatic } \\
\text { variable cylinder } \\
\text { in the both ways } \\
\text { with two } \\
\text { mechanical } \\
\text { ranges } \\
\end{array}$ \\
\hline
\end{tabular}




\begin{tabular}{|c|c|c|c|c|c|}
\hline 18 & \multicolumn{2}{|c|}{$\begin{array}{l}\text { Tractor operating weight, } \\
\text { kg, } m_{\text {tro }}\end{array}$} & 2.3 & 7235 & 7235 \\
\hline 19 & \multirow[t]{2}{*}{$\begin{array}{c}\text { Tire } \\
\text { model }\end{array}$} & $\begin{array}{l}\text { - front } \\
\text { wheels }\end{array}$ & 2.6 & & $\begin{array}{c}\text { GOODYEAR } \\
\text { TM } 818\end{array}$ \\
\hline 20 & & $\begin{array}{l}\text {-the rear } \\
\text { wheels }\end{array}$ & 2.6 & & $\begin{array}{c}\text { GOODYEAR } \\
\text { TM } 818\end{array}$ \\
\hline 21 & \multirow[t]{2}{*}{ Tire size } & $\begin{array}{c}\text { - front } \\
\text { wheels }\end{array}$ & & & $540 / 65 \mathrm{R} 28$ \\
\hline 22 & & $\begin{array}{l}\text {-the rear } \\
\text { wheels }\end{array}$ & & & 650/65R38 \\
\hline 23 & \multirow{2}{*}{$\begin{array}{l}\text { Tire } \\
\text { pressure, } \\
\mathrm{MPa}\end{array}$} & $\begin{array}{l}\text { - front } \\
\text { wheels }\end{array}$ & 2.6 & & 0,16 \\
\hline 24 & & $\begin{array}{l}\text {-the rear } \\
\text { wheels }\end{array}$ & 2.6 & & 0,16 \\
\hline 25 & \multicolumn{2}{|c|}{ Transfer number } & 3.3 .1 & & T5 \\
\hline 26 & \multicolumn{2}{|c|}{$\begin{array}{c}\text { Maximum traction } \\
\text { power, } \mathrm{kW} \\
P_{\tan }^{\max } \\
\end{array}$} & 3.3 .1 & 53,97 & 78,6 \\
\hline 27 & \multicolumn{2}{|c|}{ Traction effort, $\mathrm{kN}$} & 3.3 .1 & 23,55 & 30,2 \\
\hline 28 & \multicolumn{2}{|c|}{ Speed km/h } & 3.3 .1 & 8,25 & 9,37 \\
\hline 29 & \multicolumn{2}{|c|}{$\begin{array}{l}\text { Engine crankshaft speed, } \\
\quad \min -1, n_{e \tan }\end{array}$} & 3.3 .1 & 2000 & 2000 \\
\hline 30 & \multicolumn{2}{|c|}{ Skidding, $\%, \delta$} & 3.3 .1 & 15 & 3,5 \\
\hline 31 & \multicolumn{2}{|c|}{$\begin{array}{c}\text { Specific fuel } \\
\text { consumption, } \mathrm{g} / \mathrm{kW} \cdot \mathrm{h} \text {, } \\
\mathrm{q}\end{array}$} & 3.3 .1 & 439,8 & 302 \\
\hline 32 & \multicolumn{2}{|c|}{$\begin{array}{l}\text { Transmission efficiency } \\
\text { (grade for concrete), } \eta_{T}\end{array}$} & & 0,840 & 0,840 \\
\hline 33 & \multicolumn{2}{|c|}{$\begin{array}{l}\text { Conditional Traction } \\
\text { Efficiency, } \eta_{t r}\end{array}$} & & 0,534 & 0,777 \\
\hline 34 & \multicolumn{2}{|c|}{ Traction class } & & 2 & \\
\hline 35 & \multicolumn{2}{|c|}{$\begin{array}{l}\text { ISO Rear Mounted } \\
\text { Category }\end{array}$} & 1.6 & & CAT 2 \\
\hline 36 & \multicolumn{2}{|c|}{$\begin{array}{l}\text { Maximum lifting force of } \\
\text { the rear hinged system, } \\
\mathrm{kN}\end{array}$} & 3.2 .2 & & 60,8 \\
\hline
\end{tabular}

We sent proposals for harmonization of ISO and OECD Standards to the OECD Committee based on the research results. Aim of proposal is determination of tractive indicators for agricultural tractors according to agreed methods.

\section{Conclusions}

1. Methodology for harmonizing traction indicators of domestic and foreign tractors has been designed. It was provided an agreed assessment of tractors characteristics according to the rules OECD standard on the concrete and according to the International Standard GOST 30745-2001 (ISO) on the stubble with classification according to traction classes in accordance with GOST 27021.

2. It was designed the database of adaptation of traction tests conducted to ISO and OECD standards, obtained by theoretical and experimental methods.

3. The classification of foreign tractors (according to traction classes) allowed us to recommend the using of sets of machines for the rational using.

4. In the future, it will plane to prepare proposals of the harmonization standards of the OECD and Russian Federation for determining traction indicators of agricultural tractors. 


\section{Reference}

1. Kryazhkov V.M., Shevtsov V.G., Gurylev G.S., Lavrov A.V. Market analysis of agricultural tractors in Russia in 2008-2013 // Agricultural machines and technologies. 2014. - № 5. - p. 12-16.

2. CODE 2. OECD Standard code for the official testing of agricultural and forestry tractor performance.

3. Márquez L. Tractores Agricolas: tecnologia y utilización. Madrid: B\&H Grupo Editorial, 2012. pp. 844.

4. Polyakov O.Ya., Shilin V.E., Denyak S.M. Traction performance tractors firm "MASSEY FERGUSON" Series 8200 // Collection of works KubNIITM, Novokubansk, 2003.

5. Tabashnikov, A.T., Polyakov, OA / Indicators of tractors of foreign firms according to tests conducted in 2000-2006. in accordance with the methodology of the OECD standard, Code 1 and 2 / Informational and analytical review // Novokubansk: FGNU "RosNIITM", 2006. - 69 p.

6. Polyakov O.A., Tarnievsky V.E., Shilin V.S., Dyanyak S.M. Methods for determining the performance properties of tractors according to the traction tests carried out according to the OECD standard // Collected Works KubNITiM, Novokubansk, 2000.

7. Kryazhkov V.M., Godzhaev Z.A., Shevtsov V.G., Gurylev V.G., Lavrov A.V. Park of tractors: state and directions of development // Rural mechanization. - 2015. - №9. - pp. 3-5.

8.The Development of the Russian Agricultural Tractor Market from 2008 to 2014. Shevtsov V., Lavrov A., Godzhaev Z., Kryazhkov V., Gurulev G. SAE Technical Papers. 2016. doi: 10.4271 / 2016-01-8128.

9. Luis Márques, Dr. Ing. Agrónomo. TRACTORES AGRIOLAS: TECNOLOGIA Y UTILIZACIÓN. Impreso en España, Depósito Legal: M-2075-2012.

10. NEBRASKA OECD TRACTOR TEST 1997-SUMMARY 778 VERSATILE 305 DIESEL 16 SPEED.

11. Database "Traction indicators of domestic and foreign tractors, defined by the International (ISO) and OECD standards at the maximum operating engine power" [Text] // VG. Shevtsov, O.S. Marchenko, A.V. Lavrov, A.A. Soloveitchik, A.Kh. Tekushev, V.V. Fedyunin, E.P. Seleznev / Database Registration Certificate No. 2014620063, the date of registration is $09 / 01 / 2014$. 